\title{
"Lo que el capital se llevó": fábricas cerradas, memoria e historia reciente
}

\section{"What capital took away": closed factories, memory and recent history}

\author{
Mirta Zaida Lobato \\ mzlobato@gmail.com \\ Universidad de Buenos Aires, Argentina
}

Recepción: 11 Marzo 2021

Aprobación: 04 Abril 2021

Publicación: 03 Mayo 2021

Cita sugerida: Lobato, M. Z. (2021). "Lo que el capital se llevó": fábricas cerradas, memoria e historia reciente. Anuario del Instituto de Historia Argentina, 21(1), e135. https://doi.org/10.24215/2314257Xe135

\begin{abstract}
Resumen: Este artículo analiza las consecuencias del cierre de fábricas y los procesos de recordación que genera en la población, tomando como punto de partida los casos de los frigoríficos Armour y Swift, y la hilandería The Pattent Knitting Co., en Berisso, provincia de Buenos Aires. Desde una mirada articulada en torno a la historia local, reflexiono sobre algunos objetos culturales y experiencias de recordación desde la perspectiva de considerar esos objetos como portadores de sentimientos y emociones, entendiendo que ellos se producen y circulan en determinados contextos históricos entre diferentes grupos generacionales.
\end{abstract}

Palabras clave: Cierre de fábricas, Historia local, Procesos de recordación, Historia social del trabajo.

Abstract: This paper analyzes the consequences of factory closures and the remembrance processes they generate in the population, taking as a starting point the cases of the Armour and Swift meat packing plants and The Pattent Knitting Co. spinning mill in Berisso, province of Buenos Aires. Under an articulated look around local history, I reflect on some cultural objects and experiences of remembrance from the perspective of considering these objects as carriers of feelings and emotions and understanding that they are produced and circulate in certain historical contexts among different generational groups.

Keywords: Factory closures, Local History, Remembrance processes, Social history of work.

En este texto me propongo reflexionar sobre las consecuencias para la población del cierre de fábricas y los procesos de recordación que genera. Me concentro en el análisis de algunos objetos culturales y experiencias de recordación desde la perspectiva de considerar esos objetos como portadores de sentimientos y emociones, entendiendo que ellos se producen y circulan en determinados contextos históricos entre diferentes grupos generacionales. El punto de partida es la historia local: el cierre de los frigoríficos Armour y Swift, y la cooperativización de la hilandería The Pattent Knitting Co., en Berisso, provincia de Buenos Aires. Aunque a simple vista se podría pensar que es un problema focalizado -en lo que a falta de otro término llamaré 
desindustrialización-, está íntimamente relacionado con el desenvolvimiento político y económico nacional, y con las transformaciones de la propia industria en una escala más amplia como la internacional.

Como es conocido, la industria de la carne era clave en la economía de exportación en Argentina. Los cambios en el mercado internacional afectaron profundamente las viejas estructuras de una industria integrada verticalmente, y la falta de inversión y adecuación rápida a los cambios en la demanda llevaron a su declinación, cuando no al cierre de los establecimientos. La pequeña industria textil, en cambio, estaba conectada con la producción interna y cuando el mercado mostró sus limitaciones, en particular porque uno de los principales compradores era el Estado, su capacidad productiva se vio seriamente afectada. Estas dificultades se arrastraban desde fines de la década de 1950, se acentuaron en la siguiente y estallaron en la de 1970 (Lobato, 2001 y 2011).

Dos datos se constituyen en hitos del proceso de desindustrialización: el cierre del frigorífico Armour en 1969 y la quiebra de Swift en 1971. Así, en junio de 1972, la Cámara Nacional de Apelaciones en lo comercial confirmó el fallo del juez Salvador M. Lozada por el que se dictaba la quiebra de la Compañía Swift/Deltec. ${ }^{1}$ La firma pertenecía a un consorcio de capitales europeos y norteamericanos con sede en las Islas Bahamas y tenía numerosas empresas en la Argentina. La quiebra de Swift es una lente para analizar los debates sobre el rol del capital extranjero en el desarrollo del país y sobre el peso político de los monopolios, pero en este texto me interesa analizar las consecuencias para los trabajadores, varones y mujeres, y sus familias. ${ }^{2}$ Desde mi perspectiva de análisis, el cierre de las fábricas del grupo dio paso a un proceso histórico que no sólo ayuda a pensar el funcionamiento de la economía y de las empresas, las relaciones de poder y las decisiones de los gobernantes, sino que también da cuenta de las dramáticas situaciones que genera en las vidas de las personas. Cuando el capital "vuela" queda un vacío que es productivo, que afecta el paisaje urbano y que incide en la cultura y las sensibilidades de las personas cuyas vidas se desarrollaron en ese entorno. Pero ese proceso también se proyecta en el futuro pues ni el desenvolvimiento económico ni el proceso político posterior pudieron asegurar a los berissenses un trabajo digno. Lo más impactante fue que, de acuerdo con los datos censales de 1974, 1985, 1994 y 2004, los trabajadores industriales de Berisso disminuyeron notablemente. A mediados de la década de 1950 la localidad era una zona industrial pero después del cierre del Armour, la quiebra del Swift y la política errática de empresarios y del Estado que puso a la compañía bajo gestión estatal, y luego la privatizó para cerrar de manera definitiva en 1983, más la cooperativización de la hilandería en 1969, la privatización de la Refinería de YPF en 1993 y su posterior estatización en 2012, la convirtieron en un espacio desindustrializado. Los datos proporcionados por los censos económicos dan cuenta de la brutal caída en la cantidad de los trabajadores industriales. En 1974 había 6.174 trabajadores en la industria, en 1985 se habían reducido a 1.596, en 1996 eran apenas 906 personas, en 2004 ese exiguo número se repetía. El contraste con el pasado era brutal pues sólo en los frigoríficos llegaron a trabajar alrededor de 15.000 trabajadores en varios turnos laborales (Lobato, 2001).

Las evidencias del cambio industrial, del paisaje y de las formas de vida asociadas con el trabajo dejaron al descubierto los problemas básicos de las familias obreras. Los gobiernos que se sucedieron en la provincia de Buenos Aires y en el municipio, en diferentes versiones del peronismo, buscaban solucionar las dificultades con el establecimiento de programas sociales más que con medidas que estimularan la producción y el trabajo. Las propuestas de la creación de un parque industrial, que venían desde la elaboración del Plan Regulador (1959-1960), fracasaron en el laberinto de la política. El camino más corto fue la proliferación de diferentes programas de ayuda social que, aunque eran importantes para sus beneficiarios, modulaban políticas de corto plazo. Los programas Plan Vida, Programas Barrios Bonaerenses, Programa Empleo Comunitario, Programa Jefes de Hogar Desocupados, Seguro de Capacitación y Empleo, Plan Familias, Programa Ingreso Social con Trabajo-Argentina Trabaja -entre muchos otros- hablan de que la localidad, aunque no es la única, se convirtió en un territorio asistido por el gobierno nacional y provincial (Soldano y Costa, 2015, pp. 433-464). Cubrir las urgencias fue un modo de intervención pública aunque las dificultades se mantuvieran y se reprodujeran. 
El cierre de los frigoríficos puso al descubierto también las tensiones entre las necesidades del capital y las necesidades de la comunidad local, que vio sus bases horadadas. Los modos en los que esa comunidad lidió con los legados de la desindustrialización abren un abanico de interrogantes sobre un proceso histórico que tiene sus raíces en el peso que fueron adquiriendo los negocios financieros sobre el re-equipamiento de las empresas y el impulso a una producción acorde con la demanda del mercado de carnes, así como a las políticas que desestimulan la inversión. Aunque la palabra "desindustrialización" puede tener diferentes significados, la uso aquí para referirme al cierre de grandes empresas, al cambio del paisaje dominado por las chimeneas fabriles, a las dificultades para seguir enlazando identidad y trabajo. ${ }^{3}$

Berisso es sólo una cara de ese proceso que tiene múltiples facetas en América y en Europa. Plantas cerradas, comunidades abandonadas y el desmantelamiento de algunas industrias pueden seguirse en ciudades como Gary (Indiana) y Oakland (California) en los Estados Unidos de Norteamérica, en otras de la India y en muchas de Europa (Joshi, 2005 y Cowie y Heathcott, 2003; Swales, 2008; Taylor, 2000).

\section{OBJETOS / RUINAS}

La primera vez que fui a Berisso encontré un descampado donde antes estaba el frigorífico Armour y al frigorífico Swift en ruinas. Pregunté sobre el Swift a una persona que pasaba por la calle Nueva York y me dijo "esa mole tiene pasado". Corría el año 1985 y hacía sólo dos que el frigorífico había cerrado sus puertas definitivamente. Logré después de muchas gestiones entrar a la planta abandonada donde un pequeño grupo de trabajadores mantenía los archivos del personal y otorgaba certificaciones de trabajo. Revisé cientos y cientos de registros personales, planos, estudios de tiempo, fotografías; también caminé por sus calles internas y observé los diferentes departamentos, donde todavía quedaban las marcas de las maquinarias. El archivo fabril, lo llamé pomposamente así aunque era un espacio sucio y degradado, estaba poblado de espectros. No eran parte de un pasado momificado sino que rondaban por la fábrica y las calles adyacentes. La fábrica era como un palimpsesto en el que podía leer múltiples historias. Yo ya había elegido una: analizar las experiencias laborales y de vida, incluidas las protestas, en los dos colosos de la carne y en la pequeña textil.

La vida fluía cuando me acercaba al "descampado" del Armour porque siempre había niños o jóvenes jugando a la pelota. Cuando caminaba por la calle Nueva York para llegar adonde había estado el Armour lo hacía como si estuviera en medio de una película en la que en cada paso me cruzaba con los fantasmas de los almaceneros, peluqueras, profesoras de piano, tenderas, zapateros, quiosqueros, empleados y empleadas, pues las persianas de los negocios estaban cerradas. En ese momento me sentí impactada por la destrucción y la violencia ("los efectos colaterales") y por la potencia de los afectos que el trabajo había producido en una comunidad cruzada por múltiples conflictos. También, porque cuando analizaba los recuerdos de los trabajadores -además de caminar la localidad, conversaba con sus habitantes- "la época de trabajo" en los frigoríficos aparecía como un momento único de sus experiencias vitales. Era un ayer despojado de sus aristas negativas, sobre todo porque la falta de oportunidades laborales se sentía ya en la localidad, la incertidumbre acechaba y todo esto se intensificaría en los años por venir. En los testimonios que recogí, recordar el tiempo de esplendor, de cuando había trabajo, tenía tonos nostálgicos y elegíacos de acuerdo con los lenguajes, los objetos y los momentos de recordación.

El elemento emocional era lo que unía a los ciudadanos frente al sentido de pérdida que vivía la generación que había organizado sus vidas a partir del trabajo en las fábricas. ${ }^{4} \mathrm{El}$ sentido de pérdida era intenso y esa consternación y tristeza tuvo un momento de estallido emocional frente a la exhibición de Réquiem para un frigorifico (James y Lobato, 2020). Como hemos analizado con Daniel James en un trabajo que permanece inédito, cuando comenzó la demolición del Armour en 1985, cuando se anunciaron los mazazos destructores del viejo establecimiento abandonado, Oscar Merlano se introdujo en el edificio y fotografió lo que serían las últimas imágenes de la catástrofe. Aunque después esas imágenes pudieran reproducirse, ser observadas por distintos espectadores, ser escuchadas con diferentes tonalidades emocionales, lo que estaba haciendo 
Merlano era captar ese momento único e irrepetible de la demolición por medio de la imagen fotográfíca (Barthes, 1989, pp. 29-36). Un instante irrepetible se multiplicó en imágenes. Su ojo elegía el encuadre y los ángulos, buscaba que la iluminación hiciera hablar a los escombros. Cuando salió de la fábrica siguió fotografiando el barrio. En las fotos estaban congeladas muchas historias y su propia historia. Con el tiempo, Oscar buscó un sentido a esas fotos, trató de romper la fragmentación, de encontrar una conexión entre ellas y se unió a Raúl Figueira, historiador, escritor, político y trabajador de los frigoríficos, como todos sus hermanos, para hacerlo juntos, para que le pusiera voz. Para que rodeara de palabras los fragmentos, para que contara una historia. Seleccionaron las fotos, las pusieron en un carrusel para pasar diapositivas, buscaron la música adecuada y una voz para leer los textos, y cuando estuvo todo listo lo proyectaron ante extrabajadores y sus familias.

Réquiem para un frigorifico fue el objeto emocional, complejo por las características de su montaje, para quienes esa noche de 1985 tejían una trama afectiva organizada por el trabajo y el sentimiento de pérdida. Luego se convirtió en libro y mucho tiempo después en un audiovisual que puede verse por YouTube. Sólo se proyectó una vez y su exhibición en el presente tendría probablemente otros sentidos para los espectadores.

El documental tenía varias funciones; usos, diría John Berger en Mirar (1998). La primera capa de significación tenía ( $\mathrm{y}$ tiene) una función testimonial: dar cuenta del impacto del cierre de los frigoríficos para la comunidad. Ya he mencionado el "daño colateral" de la pérdida de empleos industriales. La ceremonia de la exhibición del Réquiem tenía también las funciones de un funeral cívico y de un duelo colectivo por la pérdida. Los funerales cívicos son frecuentes en homenajes a las "figuras ilustres". La historia argentina tiene numerosos ejemplos, desde los de Bartolomé Mitre, Carlos Pellegrini, Hipólito Irigoyen, Eva Perón y Juan Domingo Perón hasta los más recientes de Raúl Alfonsín y Néstor Kirchner (Gayol, 2012). Incluye también a figuras del espectáculo, desde Carlos Gardel a Diego Maradona. Tienen esos funerales la fuerza de las intencionalidades políticas y de las construcciones simbólicas del Estado. La capacidad política y simbólica de los cuerpos yacentes fue una herramienta poderosa para las protestas de las organizaciones obreras a principios del siglo XX (Lobato y Palermo, 2011). Luego de la represión tras una manifestación, los féretros eran acompañados en procesión hacia su sepultura. La exhibición del Réquiem fue un espacio para expresar el duelo por la muerte de los frigoríficos y de la vida misma que ellos encarnaban. Duelo en su doble sentido de aflicción pero también de generar las fuerzas para enfrentar el desafío de continuar con la vida. Lo que se ponía en juego era la posibilidad de un duelo comunitario frente a una pérdida que ya era irreparable.

Los trabajadores, varones y mujeres de todas las edades que poblaban sus departamentos, sabían que en las plantas procesadoras de carnes los ciclos de ocupación y desocupación se alternaban. Tenían la experiencia de compaginar esos ciclos con otras actividades. La demolición del Armour y el cierre definitivo del Swift hicieron evidente que no era una simple enfermedad, que el final había llegado. Era también el duelo por uno mismo: por quienes habían transitado sus caminos internos, por quienes agotaban sus fuerzas en las cámaras frías, en la playa de matanza, en la salchichería, en la estiba, en la tachería. Raúl Filgueira (1999) le puso palabras:

“[...] aún vagan por tu interior desgarrado las sombras de aquellos que se resisten a abandonarte totalmente. Aquellos que con un asombrado gesto de tus brazos tratan de encontrar una respuesta lógica para lo ilógico (...)” (pp. 7-11)

Embarcarse en el trabajo de duelo era poner un poco de orden en la recordación y encontrar respuestas a las preguntas de ese presente. Las imágenes de Merlano dialogan y se enfrentan con las palabras de Filgueira. Son formas distintas de enfrentar el duelo entre dos hijos ilustres de Berisso. Mientras las imágenes de Merlano debilitan la narrativa del valor del trabajo y el esfuerzo predominante en la comunidad, al poner el foco en un sitio convertido en escombros, las palabras de Filgueira tratan de amortiguar el sentimiento de desasosiego, procurar consuelo y transmitir alguna esperanza. Dice Filgueira:

"Aun dentro de este cono de sombras en que te han sumergido hay una puerta de luz, pupila abierta al sol como una esperanza de que tu historia no se repita. Como una esperanza nueva [...]” (Idem, pp. 11-14) 
El documental provocaba muchas emociones y recuerdos. Jaime Teixido, un obrero y dirigente comunista de base, al que visité muchas veces en su casa, a veces sola y otras con Daniel James, para conversar sobre trabajo y organización obrera, recordó que cuando miraba el documental

"pensaba en toda la gente que había muerto allí. Empecé a hacer una lista de todas las personas que había conocido [...], porque no sólo mataban animales ahí, también mataban gente [...]. Mi hermana murió de tuberculosis a los cuarenta y ocho años después de trabajar en la picada [...]. Repasé la lista [...]: fulano se cayó en las escaleras, mengano tuvo un golpe en la cabeza [...]. Mientras miraba pensaba en eso." ${ }^{5}$

Era otro modo de hacer el duelo mediante el recuerdo de esas vidas anteriores y las imágenes con las que se conectaba.

Un análisis más detallado del documental puede leerse en otro texto. Aquí sólo quiero enfatizar el sentido que la conmemoración elegíaca de la exhibición de 1985 tuvo para los espectadores de ese momento. Ese episodio local no se conectaba en ese preciso instante con otros procesos globales similares. Era vivido como un momento único, propio, singular y sólo con el estudio profundo de la significación de las imágenes y el lenguaje de Réquiem para un frigorífico, incluso reduciendo la escala del análisis a un nivel más pequeño dentro de la historia de la comunidad, pudimos establecer los nexos con ese proceso más amplio que implicó la destrucción de una forma de vida en la que el trabajo en las fábricas era el principio organizador.

Merlano y Filgueira eran "hijos ilustres" de la localidad. Filgueira escribió muchos libros de historia local, dando cuenta de una forma de hacer historia que muestra su productividad desde hace décadas en todas las regiones. En cada pueblo siempre hay una persona que junta papeles y resguarda el pasado. A veces son abiertamente generosos cuando llega un estudioso "foráneo" y otras, extremadamente cuidadosos de los documentos que salvan de la destrucción. Merlano era un cazador de imágenes con su cámara fotográfica; luego abandonó la fotografía y se convirtió en pintor. Cuando lo conocí era Secretario de Cultura en el Municipio y me ayudó a conectarme con las asociaciones de inmigrantes para organizar los grupos de recordación, en los que me contaron tantas historias de trabajo, de familias, de luchas, de persecuciones, de miserias reales y humanas, de juegos, de fiestas, de amores, de enojos, de rencillas, de chistes y bromas. No son los únicos pues existen en la localidad otros mediadores culturales.

\section{ОвJETOS / DESECHOS}

Luis Guruciaga es otro hijo ilustre local. Primero se fue convirtiendo en coleccionista de fotografías y luego de cuanto objeto tuviera alguna conexión con el pasado. Muchas cosas que quedaron de los escombros del Armour los guardó en el garaje de su casa. A su vez, la gente se desprendía de objetos (mercancías / bienes) que habían perdido su valor de uso, su capacidad de ser intercambiados. Todo lo que llegaba a sus manos lo guardaba. Con el tiempo fue pergeñando la idea de que esos objetos debían formar parte de un Museo. ${ }^{6}$ El Museo 1871 fue establecido formalmente en 2001 como un espacio de la memoria local. ${ }^{7}$ Allí la relación entre memoria y objetos es intensa. Si en el análisis de Réquiem para un frigorifico hemos sostenido que las transformaciones relacionadas con la desindustrialización estimularon la acción de agentes locales que impulsaron procesos de recordación, nostalgia y duelo, con el análisis de los objetos del Museo 1871 y de sus narrativas se puede sostener que las piezas exhibidas también generan emoción porque los objetos están atrapados en interacciones sociales. Cosas y personas tienen biografías mutuas y ellas se conectan al recorrer las salas, detenerse y observarlas, vincularlas con sus emociones y con los contextos culturales que sugiere la cartelería. La emoción que provocan los objetos en el Museo 1871 se sostiene corporalmente. Muchos relatos hablan de estremecimiento, de lágrimas contenidas, de nudos en la garganta (Lobato, 2020). Destaco, entonces, lo que una estudiosa llamó "la fuerza afectiva de las cosas" (Ahmed, 2004); en este caso, las que el museo atesora. 
El museo conserva el patrimonio cultural local con su colección de diarios, fotografías y otros objetos que refieren a la vida cotidiana, con los conflictos y tensiones que dieron forma a la experiencia de las personas que habitan la localidad. El museo modela el sentido de herencia que cobra fuerza cuando lo que era cotidiano comienza a extinguirse. Las piezas que recogía Guruciaga o que le "llovían", según su expresión, remiten a lo cotidiano: tazas de té, planchas, una máquina de coser, otra de tejer, cámaras fotográficas, juguetes, cajas de fósforos, abanicos, radios portátiles, discos de pasta y de vinilo permiten hablar de los detalles.

El Museo 1871 es lo que se llama un museo pobre y sus vicisitudes son las de una comunidad que siempre está acuciada por la urgencia de las necesidades inmediatas. Los gobiernos municipal y provincial colaboran poco (lo digo de una manera elegante) porque la inversión de recursos en una institución de este tipo no atrae a quienes buscan tener visibilidad y, además, tampoco atrae los fondos de la gran mesa de la política porque no aporta votos. La permanencia del Museo se debe a la continua donación de horas de trabajo de un conjunto de personas que lo piensa como un lugar de memoria, como un archivo del pasado de la historia local y como un espacio pedagógico para las generaciones futuras.

Si uno analiza las vicisitudes del Museo 1871 advierte que cualquier propuesta cultural está inmersa en los cambios y enfrentamientos políticos. En el particular caso de Berisso podría suponerse que la continuidad de la identidad política de los gobernantes locales no sería un obstáculo. Desde 1983 hasta 2015 todos los intendentes locales pertenecieron al peronismo, sólo que los enfrentamientos internos o la propia cultura política del partido han puesto límites a una acción mancomunada de otro tipo. Por otra parte, en una comunidad jaqueada por las dificultades económicas asociadas con el proceso de desindustrialización, los recursos destinados a la cultura son cada vez menos relevantes. Por los años noventa, más del $80 \%$ del presupuesto estaba destinado al pago de salarios y el gobierno municipal era el mayor empleador en la comunidad, con más de mil empleados y trabajadores municipales. Un porcentaje importante de los recursos provienen de las transferencias de capital de gobiernos e instituciones provinciales, y la mayor proporción en la estructura de gastos la ocupan los egresos en personal permanente, temporario, asignaciones familiares y asistencia social al personal.

Frente a estas dificultades, el Museo tiene una Asociación de Amigos y una estructura de ONG, con una comisión que estuvo presidida por Guruciaga hasta su muerte. En la actualidad, el Presidente es Oscar Rodríguez. Este funcionamiento mantiene el Museo vivo pero no resuelve sus dificultades, pues no cuenta con recursos y empleados que le permitan un funcionamiento acorde con la función que podría tener para la comunidad.

El involucramiento de los gobiernos muncipales en iniciativas de este tipo es importante y la contracara es el esfuerzo realizado en Liebig (Uruguay). El Museo de la Revolución Industrial ubicado en la fábrica del exfrigorífico Anglo en Fray Bentos preserva y transmite la herencia cultural del trabajo y de la comunidad. Está bajo la administración de la intendencia de Río Negro, que mantiene a los empleados y los capacita para la función. El Museo fue declarado, en julio de 2015, Patrimonio de la Humanidad por la UNESCO como Paisaje Cultural Industrial de Fray Bentos. ${ }^{8}$ Otro ejemplo es el Museo del Puerto, en Ingeniero White, creado en 1987, que depende de la municipalidad de Bahía Blanca y en el que se aúnan las prácticas museísticas con activos programas culturales en los que se cruzan memorias de inmigración y comidas típicas bajo la idea "Mientras cocino te cuento".

"La historia de Berisso está en el museo" dice Oscar Rodríguez, el nuevo Presidente de la Asociación de Amigos del Museo 1871. Esta idea se replica en las voces de quienes lo visitan y de quienes van a consultar los materiales que posee. El público es amplio: estudiantes de todos los niveles, historiadores, antropólogos, periodistas, escritores, grupos de jubilados y hasta los políticos locales. Es posible que así sea porque los museos cuentan historias y sus narrativas merecen un estudio más profundo.

El museo y el archivo están íntimamente entrelazados en esta experiencia comunitaria, pero a diferencia de los tradicionales museos y archivos históricos, donde la memoria es la razón del Estado, donde se almacenan 
las huellas de los poderosos, sean políticos, militares o religiosos, el museo de Berisso abarca grandes áreas de la vida social y de personas que prácticamente caen en el olvido.

\section{OBJETOS / PEDAgOgÍAs}

Los objetos son parte integral de la cultura material y las historias de las personas y los objetos se informan mutuamente. Los objetos pueden convertirse en legados por sus significaciones sociales. Pueden ser entendidos, como señala Appadurai (1991, pp.17-88) a través del análisis de los contextos culturales en que fueron producidos y en las nuevas circunstancias en las cuales adquieren significación.

La experiencia pedagógica iniciada en 2002 en la escuela primaria ubicada en la calle Nueva York se inscribe tanto en las prácticas de recordación existentes como en otras generadas en ámbitos educativos situados en localidades con patrimonios considerados "pobres" o de escaso interés por fuera de la propia comunidad, y también con las políticas públicas relacionadas con el "rescate del patrimonio cultural" (Samuel, 2008).

Frente a la pérdida de los anclajes del mundo del trabajo se indaga en el pasado algo que permita procesar la transitoriedad y volatilidad de las experiencias presentes. En los espacios educativos se busca establecer el contacto entre las generaciones y el museo se constituye en figura articuladora de las "políticas de memoria" y como una forma de combatir la división y la exclusión de sus miembros. En realidad, el museo escolar trata con la materia prima de la nostalgia por el pasado y, en parte, refuerza ese sentimiento para convertirse en vehículo del cambio social (Crooke, 2011). El Museo de la escuela de la calle Nueva York abre la posibilidad a las infancias de Berisso y a sus familias de insertarse en un intercambio simbólico de bienes culturales de los que quedaban excluidos, pues formaban parte de los nuevos habitantes de la ciudad. Lo mismo sucedió en otras comunidades obreras, por ejemplo en Pueblo Liebig, de Colón, Entre Ríos, donde los escolares pintaron en una pared "Nuestra historia es nuestro porvenir" (González, 2010, p. 156). La localidad se convirtió en capital provincial del patrimonio y de la identidad. Carteles conmemorativos y pintadas en las calles recuerdan a los visitantes esa condición.

De modo que esta escuela participó de un proceso complejo de construcción identitaria en un contexto de crisis social, económica, política y cultural porque estaba ubicada en el corazón de la sociedad del trabajo berissense en el pasado: la calle Nueva York. Con James hemos analizado en profundidad este tema. Aquí quiero destacar que docentes y niños y niñas de la escuela encontraron en la recuperación del patrimonio un modo de "hacer algo" para torcer un rumbo que los incomodaba. La escuela y su propuesta de construir un museo realizaba un trabajo pedagógico (buscar objetos, imágenes, palabras) y desarrollaba un ejercicio colectivo para reconfigurar identidades en tiempos de crisis y, de ese modo, generar cohesión. El personal docente tenía un objetivo: conformar un museo escolar que contribuyese a la conformación de la herencia cultural local y promoviera el conocimiento del pasado como un mecanismo para vencer la situación de marginación y exclusión de sus alumnos. Al mismo tiempo, trataba de acortar el vacío histórico que produce la discontinuidad producida en el mundo laboral con el cierre de las principales fábricas. En un texto clásico y extensamente citado, Maurice Halbawchs señala que cuando se produce un distanciamiento en la experiencia colectiva de un grupo, en nuestro caso como producto del proceso de desindustrialización, se abre un vacío entre la representación del pasado y la del presente. En ese momento la historia es recreada artificialmente. ${ }^{10}$ Para niños y niñas, como para sus maestras (la mayoría son mujeres), la experiencia de caminar la calle, de recrearla y de imaginarla se materializa en la conversación con los viejos vecinos. La palabra es un vehículo de la representación del pasado, así como mirar fotografías viejas posibilita el viaje retrospectivo. Mirar y recordar son las capacidades que se pusieron en juego cuando niños y viejos conversaban sobre el pasado, miraban viejas fotografías o dialogaban sobre un objeto. Todo esto se realizaba, por otra parte, en un contexto de explosión de memorias que compiten en el espacio público berissense y, también, de demandas de mejoras sociales de la población del barrio. Los objetos que en el pasado eran relevantes en la vida cotidiana, hoy en 
desuso, se almacenaban en la escuela pero, como el espacio escolar es acotado, esos materiales fueron donados al Museo 1871.

\section{ОвJETOS / BÚSQUEDAS}

Como es sabido, desde el punto de vista social la crisis de 2001 puso al descubierto la enorme llaga que se había abierto en nuestra sociedad con el tema de la desocupación. Se trata de un problema que para Berisso tiene un momento crucial con el cierre del frigorífico Armour y la quiebra de Swift/Deltec en 1969 y 1970, respectivamente. En el 2001 se puso en movimiento, como bien sostiene Ana Amado, "un activismo simbólico en distintas manifestaciones políticas" (Amado, 2009, p. 208). Esas distintas manifestaciones pueden analizarse mediante diferentes dispositivos artísticos pero en este texto quiero concentrarme en la conformación de un documental titulado "La Nueva York", pues en él se unen las dimensiones de la representación de las ruinas industriales y su entorno -el de la desocupación-, así como los modos en los que las nuevas generaciones realizan los trabajos de memoria.

El documental pone en escena, desde la primera imagen, un programa de televisión en el que un locutor / periodista dice "los piqueteros no tienen historia", una frase que sigue resonando en el presente. Entonces, si no tienen historia y están fuera del cuadro de la representación, de la economía y de la política, podría interpretarse que sus vidas precarias son también vidas desechables. Sin embargo, "La Nueva York", el documental realizado por el Movimiento de Trabajadores Desocupados (MTD) Aníbal Verón de Berisso, registra la historia de un grupo de jóvenes, de orígenes sociales diversos pero mancomunados en la búsqueda de un pasado laboral de la calle en la que viven y en el de la propia comunidad local. Como es sabido, también hay una abundante literatura sobre el origen y desarrollo del movimiento piquetero, de sus protestas y del proceso de institucionalización de las diferentes organizaciones que siguen manifestándose, ahora con más intensidad, por más planes sociales (Auyero, 2000; Pereyra y Schuster, 2008; Svampa y Pereyra, 2003; Andujar, 2014). El Movimiento de Trabajadores Desocupados fue una de las tantas organizaciones que se constituyeron inicialmente de manera autónoma de partidos políticos, sindicatos e iglesias, y que con los cortes de rutas, el bloqueo de los accesos a la ciudad de Buenos Aires y las movilizaciones por las calles céntricas y frente a organismos gubernamentales demandaban "planes de empleo" con los cuales organizar emprendimientos productivos y comunitarios. Este grupo supo organizar en Berisso dos comedores, una carpintería, dos huertas ubicadas enfrente de las ruinas del frigorífico, una biblioteca y una panadería.

Me interesa destacar que en el documental aparece con claridad la oposición entre los viejos, en su mayoría extrabajadores en esas fábricas, que miran con cierto distanciamiento a esos jóvenes que se acercan a preguntarles cómo era el trabajo en los frigoríficos y cómo era la calle Nueva York. Hay una idea que se mueve entre la mayoría de los viejos cuando dicen "Esto no tiene más retorno ni nada, todas son mentiras". Para muchos de ellos es un mundo definitivamente terminado. No son sólo imágenes y palabras de desolación, desesperanza y dolor: son también expresiones de cansancio. En el documental, las imágenes y las palabras de los entrevistados crean oposiciones. Por ejemplo, el pasado de trabajadores versus jóvenes / desocupados / piqueteros; saberes producto de la experiencia y de la edad versus la ignorancia y la juventud. Son opuestos que inicialmente no dejan entrar el papel jugado por las compañías, los gobiernos, las dictaduras, el capitalismo. La identificación de algunas dificultades entra lentamente uniendo la voz personal de los jóvenes con los desocupados, que son el pueblo, y con la ruptura de las fronteras entre lo público y lo privado. Con las imágenes podemos convertirnos en espectadores de las viviendas, los juegos, la militancia, la fabricación de pan, el trabajo en la huerta, la fabricación de ladrillos.

El relato está organizado alrededor de una pregunta sencilla: qué pasó para que la realidad de la desocupación golpeara con tanta fuerza. La respuesta dio paso a una búsqueda. Por un lado, en el conocimiento que atesoran los libros, una esperanza cifrada en el sentido pedagógico de los libros de historia, 
sean escritos por historiadores amateurs o profesionales; y, por otro, en la memoria de los viejos convertidos en guardianes del pasado.

"La Nueva York" como proceso colectivo de reconstrucción de una historia no vivida y de construcción de una historia propia se instala como un acto de rebeldía y como un momento de ruptura con el momento nostálgico de la recordación de los mayores. En esa búsqueda se toparon también con todos los estereotipos sobre el "desocupado": nunca trabajaron porque no quieren, son vagos, son ignorantes. Las palabras dichas por un entrevistado incomodan y buscan la reparación en otras imágenes: el trabajo en la panadería, en la huerta, en la carpintería, en el merendero para los niños, incluso en las movilizaciones, en la memoria de los caídos como Kostecki y Santillán. ${ }^{11}$ Las imágenes estáticas del pasado se mueven con las del presente y se funden en las movilizaciones. El sonido de la sierra mecánica de la carpintería y las voces de niños que juegan mientras gritan "piqueteros" marcan el final.

El documental tiene el carácter de una acción política que borra la diferenciación entre el hacer y el padecer. Los jóvenes realizan las imágenes y padecen las políticas. Ellos no son seres pasivos y quieren borrar los mitos que se están construyendo alrededor de las figuras de los desocupados. No interesa tanto si las imágenes del documental son "artísticas" pues de lo que se trata es de la creación de imágenes sensibles, que impregnan la política de aquello que no se quiere ver.

\section{OBJETOS / PRÓTESIS NEMÓNICAS}

El sentimiento de felicidad es uno de los más recurrentes en el imaginario peronista. Qué hace que la felicidad esté asociada a los primeros gobiernos de Juan Domingo Perón es una pregunta que muchos han respondido con un presupuesto, a veces demostrado parcialmente: el acceso a determinados bienes asociados al bienestar. Se trata de la "democratización del bienestar", en palabras de Juan Carlos Torre y Elisa Pastoriza (2002). En el sentido común de la familia peronista, el único fin del gobierno de Juan Domingo Perón habría sido la felicidad del pueblo y aquel alimenta aún a franjas importantes de la sociedad argentina. Esto soslaya otros sentimientos no tan felices de otra parte de la sociedad, que han quedado opacados. Más de 60 años han pasado desde que un golpe militar derrocó al presidente Perón. En un estudio sobre la felicidad, Sara Ahmed sugiere que la "idea de felicidad se vuelve más potente en la medida que se la percibe en crisis" (Ahmed, 2019,p. 30). En nuestro país, y en Berisso en particular, la idea de la felicidad asociada al bienestar está resquebrajada. Como he señalado en otros apartados, desocupación, precariedad, incertidumbre son palabras que dan cuenta de cuánto se ha erosionado la dupla bienestarfelicidad, particularmente con los gobiernos peronistas en la provincia de Buenos Aires y en la localidad, aunque se expresen de diferentes modos en otras provincias y pueblos.

Esa idea de felicidad pasada orienta las expectativas de diferentes grupos pertenecientes a la familia peronista. Uso expresamente la expresión "familia peronista" para dar cuenta de que es un heterogéneo arco político en el que se tejen acuerdos y desacuerdos. También he destacado en diferentes pasajes que la historia berissense es un terreno fértil para la competencia de diferentes sentidos, y el peronismo, a partir de la figura de la movilización popular del 17 de Octubre, hizo del espacio local un locus privilegiado de ese momento inaugural de su historia oficial: la movilización para liberar a Perón preso por sus camaradas de armas. Daniel James (1987) ha analizado profundamente la significación de esos acontecimientos en Berisso y La Plata.

Sin embargo, Berisso ya no es el espacio laboral que dio origen al peronismo, aunque esta expresión encierra una idea de monopolio de un suceso que se hizo sentir en otros lugares alrededor de la Capital Federal y generó inquietud casi en todo el territorio nacional. Una ya abundante literatura nos ha hecho reflexionar sobre los pasos seguidos en muchas provincias en la configuración de un nuevo movimiento político que se nutría también de dirigentes e ideas de otras fuerzas políticas. Tampoco lo es la calle que corría paralela a los dos establecimientos cárnicos locales. La calle Nueva York, otrora bulliciosa, cosmopolita y activa, muestra muchas de las llagas sociales de la actualidad. En la calle se libran batallas de sentidos que merecen ser 
analizadas en profundidad. Puedo decir que conozco esa calle en un complejo juego de aristas: en muchísimas oportunidades hablé con trabajadores, comerciantes e integrantes de sociedades étnicas, revisé los papeles del Club Zona Nacional y del Hogar Obrero, hablé con maestros, maestras, autoridades de la escuela que promovió entre sus alumnos y alumnas una recuperación de la historia de la calle, revisé periódicos locales y nacionales.

El proyecto de patrimonialización de la calle Nueva York lo hemos analizado con Daniel James en otro texto y tiene numerosas caras. Fue una iniciativa local promovida por Alberto Nicoloff, otro de los hijos dilectos de la localidad, allá por el año 2000 aunque se concretó en 2005. A Nicoloff lo entrevisté cuando yo tenía como objetivo de investigación el análisis de las experiencias obreras en las industrias de la carne y textil de Berisso. La propuesta de patrimonialización tenía como objetivo dinamizar la zona e impulsar el turismo. Por cierto que el proyecto competía con otras ideas de revitalización económica, como por ejemplo el proyecto portuario y la terminal de contenedores. Esta terminó realizándose y ello afectó profundamente el proyecto de recuperación patrimonial de la calle Nueva York. ${ }^{12}$ Hoy está más deteriorada que cuando la Asociación Amigos de la calle Nueva York inició las gestiones para poner en valor la zona.

El deterioro de los edificios y fachadas de la calle es importante. Aparecieron muchos espacios baldíos y hay casas derruidas, además de la histórica acumulación de basura y aguas estancadas. En la esquina de Marsella y Nueva York, la Asociación de Amigos de la calle convirtió un espacio vacío en plazoleta, que lleva el nombre de Alberto Nicoloff. El día que la visité en 2018 un caballo pastaba tranquilamente entre una pintura mural estropeada y un monolito con los tópicos clásicos del peronismo: las figuras de Evita y Perón, el escudo del Partido Justicialista, la fachada de la mansión de obreros de Berisso de 1920. El espacio está señalizado como "Kilómetro 0 del peronismo". En el mural, en cambio, aún podía verse el tranvía que llegaba lleno de trabajadores, hombres y mujeres, cada mañana. El monumento tiene una placa recordatatoria, colocada en 2015 por el presidente del Partido Justicialista local y el intendente Enrique Slezak al cumplirse 60 años de un acontecimiento que se considera un momento fundacional de ese movimiento político. Hasta 2015, en Berisso nunca gobernó otro partido político cuando se realizaron elecciones democráticas. En 1973 ganó el Frente Justicialista de Liberación, luego vino la larga noche de la dictadura y desde 1983 hasta 2015 todos los gobernantes fueron de ese origen. También es necesario decir que "Kilómetro 0 del peronismo" es el nombre de una de las corrientes internas dentro de ese grupo político. El monumento está en diálogo con otra placa colocada en la puerta del viejo bar Dawson, que ahora funciona como “Centro cultural Raíces”. La placa conmemorativa fue colocada por el presidente del Partido Justicialista de la provincia de Buenos Aires, Fernando Espinoza, en octubre de $2016 .{ }^{13}$ Las palabras recordatorias dicen:

\footnotetext{
"Se repitió aquí el caso de Belén, hace dos mil años; los primeros en creer fueron los humildes, no los ricos, ni los sabios, ni los poderosos. Es que los ricos y sabios y poderosos deben tener el alma casi siempre cerrada por el egoísmo y la avaricia. En cambio los pobres, lo mismo que en Belén, viven y duerme al aire libre y las ventanas de sus almas sencillas están casi siempre abiertas a las cosas extraordinarias".
}

La plazoleta y el monumento son lugares de memoria que nos permiten pensar la complejidad que tienen como objetos con historias diferentes y significaciones culturales también diversas. Son lugares materiales, simbólicos y funcionales, y como dice Pierre Nora (2008, p. 33): "sólo es lugar de memoria si la imaginación le confiere un aura simbólica”. Para la Asociación Amigos de la Calle Nueva York esa aura era encontrar un destino diferente al de una ruina industrial, a una experiencia de vida carcomida luego del cierre de las fuentes de trabajo; para el Partido Justicialista, en cambio, era la cristalización de un momento del pasado. Una fecha del calendario que había perdido parte de sus anclajes del pasado. Su significado tenía un aura astillada, la potencia de su significación no podía repetirse porque el peronismo local estaba dividido y además habían perdido por primera vez una elección en la localidad. Cuando en octubre de 2016 colocaban una placa en la fachada del bar Dawson no sabían que esa situación iba a ser efímera y cristalizaban un recuerdo para transmitirlo a quienes no habían participado del suceso. Bloqueaban el trabajo de olvido, reactualizaban el 
enfrentamiento entre humildes y ricos, sabios y poderosos. No podemos saber cuál es la capacidad que tienen esas palabras y otros actos para restituir el aura de la unidad y la lealtad del partido Partido en un contexto económico político y social diametralmente opuesto, pero sí sabemos por las enseñanzas de Nora que "los lugares de memoria no viven sino por su aptitud para la metamorfosis, en el incesante resurgimiento de sus significaciones y la arborescencia imprevisible de sus ramificaciones" (Nora, 2008, pp. 33-34).

\section{COMENTARIO FINAL}

He tomado en la escritura de este texto una idea de Igor Kopytoff (1991) para enfatizar que los objetos (las cosas en sus palabras) tienen historia, forman parte de la cultura material, crean sentidos, se mueven, y son portadores de emociones. Esos objetos sostienen el dolor, el rechazo, el miedo y construyen nociones sobre el amor al pueblo y el odio al que lo explota. También he dado cuenta de que los objetos se valorizan y singularizan convirtiéndose en patrimonio, como por ejemplo el proyecto de conservación de la calle Nueva York y su refuncionalización, o se sacralizan y entran en un museo. En este texto, los objetos son una forma de negociación de la memoria colectiva en una comunidad que sufrió el impacto de la desindustrialización en una sociedad capitalista.

Además, medianteel análisis de algunos de esos objetos, fui relacionándolos con pedagogías y búsquedas en las que se cruzaban generaciones: adultos, jóvenes e infancias. La exploración de esos textos culturales constituidos por capas de historicidad nos coloca también frente al dilema de pensar el pasado "reciente" en sus complejidades conceptuales y metodológicas, pero asimismo a considerar que ese pasado excede la problemática traumática de la última dictadura militar expresada en la violación de los derechos humanos para abarcar otros territorios e incorporarlos a la reflexión.

La escala de análisis también es relevante. La comunidad obrera de Berisso fue construida como tal en las primeras décadas del siglo XX en un conflictivo proceso de inclusiones y exclusiones y de vínculos con lo nacional y lo global. Esa comunidad tuvo diferentes momentos de resignificaciones, como he mostrado en otro texto (2001). La actividad económica que vertebró el mundo del trabajo fue la industria de la carne y ella estaba íntimamente vinculada con el mercado internacional. La demanda de brazos se cubrió con la llegada de miles de personas que bajaron de los barcos que cruzaban el océano Atlántico y de otras tantas que descendieron de los trenes procedentes de otras regiones del país. Las formas en las que se desenvolvieron los negocios de empresas de capital extranjero como Swift y Armour enlazan diferentes espacios dentro del país y fuera de nuestro territorio. La búsqueda de ganancias rápidas vía los negocios financieros y la quiebra de la compañía afectaron profundamente la vida comunitaria. Cuando eso se produjo, se activaron diferentes procesos de recordación, en los cuales los objetos jugaron un rol importante como soportes de memorias y de diferentes tonos emocionales. A través del análisis de distintos objetos culturales y de sus significaciones, la escala de análisis se fue moviendo de lo más cercano a lo distante, de lo local (Berisso) a la Nación (Argentina) e incluso a un nivel más amplio, como los negocios financieros con sede en paraísos fiscales como Bahamas. La escala de análisis también fue mudando para tomar diferentes objetos y experiencias que estaban insertos en una malla más amplia de significaciones dentro y fuera de la comunidad. Berisso se toma aquí como una estrella que no hace el firmamento pero sin la cual no podemos dimensionar el cielo (lo que el capital nos dejó).

\section{Fuentes DOCUMENTALES}

Municipalidad de Berisso (1960-1969). Berisso, Plan Regulador, Vols. 1, 2 y 3. Museo del puerto, Ingeniero White (2005). “Boletin”, n² 2 
MTD Berisso (2005). Documental La Nueva York. Idea original, producción, fotografía: Bruno Pianzola. Dirección, producción, guion, montaje, cámaras: Agustín Samprún. Producción ejecutiva: "Wichi”.

Filgueira, R. (1999). Réquiem para un frigorifico. Buenos Aires: Instituto de Cultura Latinoamericana.

Movimiento de Trabajadores Desocupados Aníbal Verón (2003). Dario y Maxi. La dignidad piquetera. Buenos Aires: Ediciones 26 de junio de 2003.

AA.VV. Proyecto de Patrimonialización de la Calle Nueva York. Asociación Amigos de la calle Nueva York. Municipalidad y Colegio de Arquitectos de la provincia de Buenos Aires. Municipalidad de Berisso, Intendente: Enrique Slezack. Asociación Amigos de la Calle Nueva York. Presidente: Alberto Nikoloff, Presidente Honorario: Lito Cruz. Colegio de Arquitectos de la Provincia de Buenos Aires - Distrito I, Presidente: Juan José García Olivares. Grupo de Trabajo: Municipalidad de Berisso, Bajcic Juan, Kochanowsky Claudia (Coordinador), Navickas Mónica, Onofri María Silvina, Román Daniel, Stangatti Luis (Coordinador); Asociación Amigos de la Calle Nueva York, Bajcic Juan José, Brieva Juan, Brebo Juan, Caimi Graciela Marta, Di Paolo Stella, Durand Carlos, Gómez Olga, Nikoloff Alberto (Coordinador), Petit Marta Susana, Sánchez Marcela, Sansó Xavier, Simoncini Susana, Zubiaga Alicia (Coordinador). Colegio de Arquitectos de la Provincia de Buenos Aires - Distrito I, Aguilar Graciela (Coordinador), Belloni Patricia, Cattera Claudio, del Barrio Diana, Dicroce Luciano, Diluca Valeria, Domínguez María Cristina (Coordinador), Ferreyro Carlos, García Olivares Juan José, Gorelik Ricardo, Koller Evangelina, Martínez Carolina, Michellod Oscar, Vicente Rubén, Villani Sergio, Zuloaga Germán.

Filgueira, R. y Merlano, O. (1999). Réquiempara un frigorifico. Montaje audiovisual (textos: Raúl Filgueira; fotografías: Oscar Merlano). Buenos Aires: Ediciones ICLA. Disponible en https://www.youtube.com/wa tch?v=uERwCAeEGqg

Lobato, Mirta Zaida (1987-1989). Entrevistas a Jaime Teixido. Berisso, 12 de marzo de 1987, 28 de octubre de 1988 y 22 de junio de 1989.

Lobato, Mirta Zaida (2009-2014). Entrevistas con docentes de la Escuela $N^{\circ} 9$ "América”. Berisso, 5 y 19 junio de 2009, 13 y 27 de junio de 2014.

\section{REFERENCIAS}

Andújar, A. (2014). Rutas argentinas hasta el fin. Mujeres, politica y piquetes, 1996-2011. Buenos Aires: Luxemburg. Ahmed, S. (2004). Affective economies. Social Text, 79(22: 2), 117-139.

Ahmed, S. (2019). La promesa de la felicidad: una crítica cultural al imperativo de la alegría. Buenos Aires: Caja Negra. Amado, A. (2009). La imagen justa. Cine Argentino y politica (1980-2007). Buenos Aires: Colihue.

Appardurai, A. (Ed.). (1991). La vida social de las cosas. Perspectiva cultural de las mercancías. México: Grijalbo.

Auyero, A. (2000). La protesta. Relato de la beligerancia popular en la Argentina democrática. Buenos Aires: Los libros del Rojas.

Barthes, R. (1989). La cámara lúcida. Nota sobre la fotografía. Barcelona: Paidós.

Berger, J. (1998). Mirar. Buenos Aires: Ediciones de la Flor.

Boyer, M. C. (1996). The City of Collective Memory. The Historical Imaginary: an Architectural Entertainment. Cambridge: The MIT Press.

Cowie, J. y Heathcott, J. (Eds.). (2003). Beyond the Ruins. The Meaning of deindustrialization. Ithaca: ILR Press.

Crooke, E. (2011). Museums and Community. En S. Macdonald (Ed.), Companion to Museum Studies (170-185). Wiley-Blackwell: Chisester.

Gayol, S. (2012). La celebración de los grandes hombres: funerales gloriosos y carreras post mortem en Argentina. Quinto Sol. Revista de historia, 16(2), 1-29.

Gresores. G. (2000). De cabeza de león a cabeza de ratón: el caso del Swift, 1957-1980. Cuadernos del PIEA, 13, 97-138. 
Gresores, G. (2002). El caso Swift Deltec. Un capítulo escandaloso en la historia del capital norteamericano en la industria frigorífica de la Argentina. Realidad Económica, 191, 1-18.

González, A. (2010). Escuela y patrimonio local: activación en contextos de vulnerabilidad social. Tesis de Maestría. Buenos Aires: FLACSO.

James, D. (1987). 17 y 18 de octubre: el peronismo, la protesta de masas y la clase obrera argentina. Desarrollo Económico, 107(27), 445-461.

James, D. y Lobato, M.Z. (2020). After the Catastrophe: Requiem para un Frigorífico. Photography andCulture, 13(2). 157-173.

Joshi, C. (2005). Lost World. Indian Labor and its forgotten histories. Londres: Anthem Press.

Kopytoff, I. (1991). La biografía cultural de las cosas. La mercantilización como proceso.En A. Appardurai (Ed.), La vida social de las cosas. Perspectiva cultural de las mercancías (pp. 89-122). México: Grijalbo.

Lobato, M. Z. (2001). La vida en las fábricas. Trabajo, protesta y politica en una comunidad obrera. Berisso, 1904-1970. Buenos Aires: Prometeo.

Lobato, M. Z. (2011). El trabajo en la industria textil de Berisso. Revista de Historia Bonaerense, 38, 2-10.

Lobato, M. Z. (2020). Comunidades, historia local e historia de pueblos. Huellas de su formación. Buenos Aires: Prometeo.

Lobato, M. Z. y Palermo, S. (2011). Del trabajo a las calles: dignidad, respeto y derechos para los y las trabajadoras. En M. Z. Lobato (Ed.), Buenos Aires: manifestaciones, fiestas y rituales en el siglo XX. Buenos Aires: Biblos.

Nora, P. (2008). Les Lieux de mèmoire. Montevideo: Trilce.

Nussbaum, M. C. (2014). Emociones politicas. ¿Por qué el amor es importante para la justicia? Barcelona: Paidós.

Pereyra, S., Pérez, G. y Schuster, F. (Ed.). (2008). La huella piquetera. Avatares de las organizaciones de desocupados después de 2001. Buenos Aires: Ediciones Al Margen.

Samuel, R. (2008). Teatros de la memoria. Pasado y presente de la cultura contemporánea. Valencia: Universidad de Valencia.

Swals, J. (2008). Lying in wait to be found: Reliquary Communities of Memories. Nordlit, 23, 337-353.

Soldano, D. y Costa, M. I. (2015). El conurbano como territorio asistido. Pobreza, crisis y planes sociales (pp. 433-463). En Kessler, G. (Dir.), Historia de la Provincia de Buenos Aires. 6, El Gran Buenos Aires. Buenos Aires: UnipeEdhasa.

Svampa, M. y Pereyra, S. (2003). Entre la ruta y el barrio. La experiencia de las organizaciones piqueteras. Buenos Aires: Biblos.

Taylor, I. (2000). European Ethnoscapes and Urban Revedelopment. The reutrn of Little Italy in 21st century Manchester. City, 4(1), 27-42.

Ursino, S. V. (2020). Trabajo industrial y dinámicas socioterritoriales en las ciudades de Ensenada y Berisso. El caso de la Refinería YPF-La Plata (1993-2012). Estudios Socioterritoriales. Revista de Geografía, 28, 1-24.

\section{Notas}

1 Las alternativas del caso pueden seguirse en La Opinión, 11 de marzo, 7 y 14 de junio de 1972; La Nación, 10 y 21 de junio de 1972; Clarin, 2 de junio y 5 y 7 de julio de 1971.

2 La literatura histórica y sociológica se concentra en el estudio de los monopolios de capital norteamericano y en algunas de las protestas que se produjeron luego de la quiebra del grupo Swift-Deltec (Gresores, 2000 y 2002; Ursino, 2020, entre otros autores).

3 Algunos economistas usan términos como "re-estructuración", "achicamiento" o "destrucción creativa".

4 Para un análisis de las emociones, aunque desde perspectivas diversas, Nussbaum, 2014, pp. 14-15 y Ahmed, 2015.

5 Entrevista a Jaime Teixido, Berisso, 22 de junio de 1989.

6 Véase http://museo1871berisso.org.ar/

7 Hemos realizado con Daniel James un análisis de la formación del Museo 1871 y de los rasgos del coleccionismo de Luis Guruciaga en el estudio aún inédito "Narraciones comunitarias: memorias, museos y fiestas". 
8 http://www.elpais.com.uy/informacion/frigorifico-anglo-patrimonio-humanidad-unesco.html

9 https://www.ingenierowhite.com/museo-del-puerto/

10 Citado en Boyer, 1996, p. 133.

11 El 26 de junio de 2002 se produjo el asesinato de Maximiliano Kostecki y Darío Santillán en Avellaneda (Argentina), durante una movilización por un aumento general de salarios y de los subsidios para los desocupados, por más alimentos para los comedores populares y en solidaridad con los trabajadores de una fábrica de cerámica. En la manifestación participaban activamente trabajadores desocupados. Los acontecimientos están relacionados además con la crisis política y económica de 2001. La filmación de los noticieros televisivos y las fotografías de prensa fueron importantes para la investigación judicial. Véase Movimiento de Trabajadores Desocupados Aníbal Verón (2003).

12 El puerto de contenedores fue inaugurado en 2015 por el entonces gobernador de la provincia Daniel Scioli y candidato presidencial en las elecciones de ese año.

13 Fernando Espinoza fue durante 10 años intendente de La Matanza, diputado nacional entre 2017 y 2019 y Presidente del Partido Justicialista de la provincia de Buenos Aires entre 2013 y 2017. 